\title{
Dos pactos políticos à política dos pactos na saúde
}

\author{
From political pacts to health policy pacts
}

Jória Viana Guerreiro ${ }^{1}$

Maria Alice Fernandes Branco ${ }^{2}$

${ }^{1}$ Departamento de

Promoção da Saúde, Centro

de Ciências Médicas,

Universidade Federal da

Paraíba. Cidade

Universitária, Campus I, $1^{\circ}$

andar do Centro de Ciências

da Saúde. 58051-900 João

Pessoa PB.

joria2005@yahoo.com.br

${ }^{2}$ Centro de Pesquisas Aggeu

Magalhães, Fundação

Oswaldo Cruz.
Abstract The object of this article is the pact policy of the Unified Health System (SUS). The few works available in the literature about health pacts frequently relates them to the principles of SUS consolidation, specifically to the implantation of decentralization. Here, the roots of this policy are evidenced showing how they are linked with the restructuration movement of the proper Brazilian State in the last decades from the $20^{\text {th }}$ century, by democracy rebuilding, federalism and State Reform. During this period, some advances in politics democracy were identified, however a few results in consolidation of social democracy were identified. Health pacts are articulated with social and political pacts, which are essential to make life possible in society, guarantee government legitimacy, governance and public policies effectiveness. Pact is a management mechanism that comprehends permanent negotiation, looking for surpasses intergovernmental conflicts, moderate by solidary responsibility. Throughout negotiation of goals, indicators and actions, pacts consist in a way of accountability and transparency, able to promote social control, and the own government control.

Key words Pact, Policy, Health management pact, Intergovernmental alliances
Resumo Este artigo tem como objeto a politica de pactuação do Sistema Único de Saúde (SUS). Os poucos trabalhos na literatura sobre pactos na saúde frequentemente os relacionam à consolidação dos princípios do SUS, especificamente à implantação da descentralização. Aqui são evidenciadas as raízes dessa política, mostrando-se como estão articuladas ao movimento de reestruturação do próprio Estado brasileiro, ocorrido nas últimas décadas do século XX, por meio da reconstrução da democracia, do federalismo e da Reforma do Estado. Neste período, são identificados avanços na democracia política, porém pouca evolução na consolidação da democracia social. Os pactos na saúde articulam-se aos pactos sociais e políticos, estes últimos essenciais para tornar possível a vida em sociedade, garantir a legitimidade dos governos, a governabilidade e a efetividade das políticas públicas. A pactuação é um mecanismo de gestão que compreende negociação permanente, buscando a superação dos conflitos intergovernamentais, pautada pela responsabilização solidária. Por meio da negociação de metas, indicadores e ações, os pactos se constituem numa forma de accountability $e$ transparência, capaz de favorecer o controle social e o do próprio governo.

Palavras-chave Pacto, Politica, Pacto de gestão na saúde, Relações intergovernamentais 


\section{Introdução}

Durante o processo de consolidação do Sistema Único de Saúde (SUS), ao longo de seus vinte anos de existência, ocorreram transformações na organização do sistema de saúde brasileiro. Dentre estas, a realização de pactos intergestores destaca-se como fato inovador na gestão da saúde. Representa uma proposta de ação pautada em princípios dialógicos que envolvem a responsabilização solidária e mecanismos que favorecem a transparência das ações, a accountability e o controle social.

As raízes dos pactos de gestão do SUS são evidenciadas neste artigo, partindo-se do entendimento de que o setor saúde insere-se num contexto maior da sociedade, que sofre influências das transformações no perfil e no papel assumidos pelo Estado ao longo da história. As origens da política de pactuação na saúde encontram-se no movimento mais amplo de reestruturação do Estado brasileiro, ocorrido nas últimas décadas do século XX: a consolidação da democracia, a reconstrução do federalismo e a reforma do Estado.

Elementos facilitadores para a construção desta política também são encontrados no âmbito do setor saúde. Dentre os aspectos internos ao SUS, destacam-se: o processo de descentralização político-administrativa, a criação de instâncias de decisão e pactuação e o estabelecimento da Programação Pactuada Integrada (PPI).

Os pactos intergestores do SUS relacionamse a outros pactos existentes na sociedade: o sociopolítico e o federativo. O pacto sociopolítico é o mais amplo, do qual os outros dependem. Nele estão envolvidos o Estado, os trabalhadores, a sociedade civil e a organizada. Sua finalidade é legitimar os governos, assegurar a governabilidade e a efetividade das políticas públicas, garantindo o funcionamento da sociedade. Por seu turno, o pacto federativo inclui a divisão de poder, de recursos e de competências entre os entes federados (União, estados e municípios), buscando-se uma parceria no alcance dos interesses nacionais, regionais e locais. O pacto de gestão do SUS refere-se ao compartilhamento de responsabilidades no desenvolvimento de ações e serviços de saúde, de maneira solidária, entre as esferas de governo, e ao compromisso com o cumprimento de metas e diretrizes, previamente definidas.

\section{Pactos sociais}

A noção de pacto social remonta ao século XVII, a partir das ideias de Thomas Hobbes ${ }^{1}$ (15881679), contidas principalmente nas obras Sobre o cidadão e Leviatã. Segundo esta concepção, os homens não vivem em cooperação natural, como as formigas ou abelhas, cujo acordo é natural. Para os homens, esse acordo só pode ser artificial. O estado natural é de insegurança e angústia para todos, havendo sempre o temor da morte ou da escravidão, pois neste contexto não existem normas, regras, padrões de comportamento ou leis. O que importa são as ações no sentido de preservar a própria vida, mesmo que isso signifique a morte dos outros. A competição gerada entre os homens se configuraria em uma "guerra de todos contra todos", ameaçando a preservação da vida.

Para se conseguir a paz, torna-se necessário o estabelecimento de um contrato social, realizando-se uma transferência mútua de direito: os homens aceitam abandonar a capacidade de atacar os outros em troca do abandono, pelos outros, do direito de os atacarem.

Com o pacto, o homem é introduzido em uma ordem moral, visto que, no estado natural, as ideias de justiça e moral não fazem sentido. $\mathrm{O}$ pacto social é artificial e precário, não sendo suficiente para garantir a paz, havendo a necessidade de serem estabelecidos mecanismos que obriguem o seu cumprimento. Para tanto, Thomas Hobbes ${ }^{1}$ propõe a entrega do poder a um soberano, que seria a própria fonte legisladora e não se submeteria a nenhuma lei, devendo prestar contas apenas a Deus. Para a garantia da paz, todos devem se submeter a este poder, que pune aqueles que o quebrem, pois "os pactos sem a espada não passam de palavras" ${ }^{\text {. }}$

A importância do pacto, segundo a filosofia hobbesiana, é a de proporcionar condições de existência para todos, além de explicitar os direitos dos indivíduos e o exercício do poder na sociedade civil. $\mathrm{O}$ acordo serve, portanto, para garantia da paz e da segurança, resultando em leis que devem ser obedecidas por todos e na instituição de um poder, com a finalidade de tornar possível o cumprimento dessas leis.

Em oposição às ideias de Thomas Hobbes ${ }^{1}$, Jean Jacques Rousseau ${ }^{2}$ (1712-1778) apresentou a visão de que o homem é naturalmente bom, livre e igual aos outros homens. Mesmo desigualmente dotado pela natureza, não encontrava motivos para competir, pois o ambiente natural satisfazia a necessidade de sobrevivência. 
Encontra-se no pensamento deste filósofo a defesa do "homem pacífico na natureza" e do "homem bélico" na sociedade, pois a vida em sociedade é que despertaria no homem o egoísmo e a disputa por sobrevivência, tendo a guerra como consequência.

Thomas Hobbes ${ }^{1}$ percebe na criação de um Estado forte e centralizado o recurso para proteção e defesa da sociedade contra a "guerra de todos contra todos". Para Jean Jacques Rousseau ${ }^{2}$, a guerra não é inerente à natureza do homem, mas consequência da vida em sociedade, que gera competição e conduz ao conflito. A criação de um Estado, portanto, não reduzirá as tensões ou a violência; um Estado forte ameaçará a paz pela compulsão da conquista, um fraco tornar-se-á tentação para a cobiça alheia.

A ideia de contrato social em Jean Jacques Rousseau ${ }^{2}$ é de uma livre associação de seres humanos inteligentes, que deliberadamente resolvem formar um certo tipo de sociedade, à qual passam a prestar obediência mediante o respeito à vontade geral. O Estado é, então, resultado de um contrato social, no qual os indivíduos não renunciam a seus direitos naturais, mas, ao contrário, entram em acordo para a proteção desses direitos. O contrato social dá-se por meio de um pacto estabelecido entre o povo e os governantes, que ficam submetidos à "vontade geral". Dessa forma, o Estado expressa a "vontade geral”, não sendo apenas a soma das vontades individuais, que se volta para o "bem comum". É essa "vontade geral" que dota o Estado de força para que ele atue em favor das teses fundamentais, mesmo quando isto significa ir contra a vontade da maioria em alguma questão particular.

À maneira de Thomas Hobbes ${ }^{1}$, Jean Jacques Rousseau ${ }^{2}$ defende a utilização de sanções que acreditava serem necessárias para a manutenção do contrato social e, consequentemente, da estabilidade política do Estado por ele preconizado. Propõe a obediência a este contrato ou a pena de morte aos que não obedecerem a ele.

Embora divergentes, interessa nesta discussão o ponto em que as ideias dos dois filósofos concordam: a necessidade de um pacto social, capaz de tornar possível a vida em sociedade.

Levando-se em conta a conjuntura das sociedades capitalistas atuais, a existência de países em estágios diferentes de desenvolvimento e o papel do Estado em cada um deles, pode-se observar que a questão do contrato social torna-se mais complexa do que nos tempos de Thomas Hobbes, quando prevalecia uma economia mercantilista.
A existência de acordos, na atualidade, tem o objetivo de legitimar governos, assegurar a governabilidade e garantir a efetividade das políticas públicas, principalmente das econômicas. Salienta-se que o acordo não elimina o conflito distributivo, apenas o controla, dependendo do papel da sociedade civil, pois, quando é débil ou incompleto, como na maioria dos países em desenvolvimento, os obstáculos políticos para elaboração e implementação de políticas econômicas tornam-se evidentes ${ }^{3}$.

\section{Pactos políticos e sociais no Brasil}

Os pactos políticos são alianças de classes ou frações de classes que se formam para o exercício efetivo do poder político. Os pactos sociais seriam acordos realizados entre os trabalhadores e a burguesia, com vistas à manutenção da ordem social e econômica. O pacto político está interligado ao social, pois pressupõe a sua existência e reconhece que as classes sociais tendem a dividirse por conta da disputa do poder do Estado ${ }^{4}$.

O Pacto de Moncloa é um dos mais conhecidos da sociedade capitalista contemporânea. Realizado na Espanha, em 1977, entre líderes trabalhistas e empresariais, marcou a passagem da ditadura franquista à nova democracia espanhola. A estabilização da economia e a retomada do crescimento são apontadas como pontos positivos deste pacto, que também é alvo de críticas, especialmente pela precarização do emprego e por debilitar o movimento sindical, pelas concessões feitas aos empresários. Na realidade, registra-se que, entre 1977 e 1984, foram firmados seis grandes pactos pelo governo espanhol, buscando consolidar a democracia naquele país.

Em nível mundial, foi proposto pelas Nações Unidas, em 1999, durante a realização do Fórum Econômico Mundial (em Davos), um Pacto Global com o objetivo de mobilizar a comunidade empresarial internacional para a promoção de valores fundamentais nas áreas de direitos humanos, trabalho, meio ambiente e de combate à corrupção. Esta iniciativa conta com a participação de agências das Nações Unidas, empresas, sindicatos, organizações não governamentais e demais parceiros necessários para a construção de um mercado global mais inclusivo e igualitário. Não tem um caráter obrigatório ou regulador nem oferece certificação aos que cumprem com os requisitos. A instituição que adere ao Pacto Global assume voluntariamente o compromisso de implantação de princípios previamente definidos. 
No Brasil, são apontados por Luiz Carlos Bresser-Pereira ${ }^{4}$ grandes pactos políticos e sociais no período pós-industrialização, iniciado nos anos 30 do século XX.

Entre os anos 1930 e 1960, constituiu-se o pacto populista: uma aliança entre a burguesia industrial, os trabalhadores e a tecnoburocracia estatal. Representou a substituição das velhas oligarquias exportadoras por setores agrários e indústrias mais voltadas para o mercado interno, num contexto de implementação do processo de industrialização no país.

A partir da década de 1960, com a crise das economias latino-americanas, que resultou na superação do modelo de industrialização substitutiva de importações e na abertura da economia daqueles países para o mercado internacional, estabeleceu-se um novo pacto no Brasil: o autoritário tecnoburocrático-capitalista. Constituiu-se a partir do golpe militar de 1964, sob a égide das empresas multinacionais manufatureiras que, aliadas ao capital industrial local e à tecnoburocracia estatal, civil e militar, favoreceu a consolidação do capitalismo oligopolista no país.

No início dos anos 1980, eclodiu mais uma crise da economia latino-americana, caracterizada pela elevação das dívidas externas, da inflação e por forte redução do produto interno bruto (PIB) e da renda per capita. Somando-se a esta crise, a perda de legitimidade do regime militar ante a sociedade civil e o papel desempenhado pelas lutas populares em favor da democracia provocaram o rompimento da aliança do capital industrial com a tecnoburocracia estatal e, consequentemente, do pacto autoritário tecnoburocrático-capitalista. Configurou-se o pacto social democrático, tendo como base três princípios"

(1) redemocratização, que interessava a todos;

(2) manutenção do capitalismo, que interessava à burguesia;

(3) moderada distribuição de renda, interesse dos trabalhadores e das esquerdas.

\section{Pacto federativo e descentralização}

O pacto social democrático ajudou a criar as condições para o desenvolvimento da democracia no país, que se iniciou com a instituição das eleições diretas para governadores, em 1982, e para presidente, em 1989. Este pacto é marcado pela descentralização política, administrativa e financeira.

Após a promulgação da Constituição, em 1988, um novo modelo federativo passou a vigorar, tendo como resultado uma série de avan- ços em torno das políticas públicas. No entanto, os progressos conseguidos na esfera da democracia política não foram extensivos à democracia social, ao persistirem, no início do século XXI, a elevada concentração de renda, desigualdades socioeconômicas e altas taxas de desemprego na sociedade brasileira.

O federalismo implantado no país ampliou a autonomia municipal, no contexto da organização política brasileira. O modelo tridimensional, que conta com a existência de três entes políticos internos e autônomos - União, estados e municípios -, é peculiar ao Brasil, comparando-se com outros países que também possuem uma organização federativa. Evidentemente, a configuração desta estrutura federativa produziu influências no desenho e na gestão das políticas públicas.

A transformação do município em ente federado, portador de autonomia administrativa e financeira, trouxe como consequência a necessidade de redistribuição de competências para a prestação de serviços públicos entre as três esferas da federação. Entretanto, os estados e municípios são extremamente dependentes de um poder central e competem predatoriamente por recursos para o exercício dessas competências ${ }^{5}$.

A discussão sobre a distribuição de competências está indispensavelmente ligada à alocação e divisão de recursos financeiros necessários à execução delas. O desequilíbrio fiscal impõe dificuldades de transferência de recursos e competências, como também obstáculos à formulação de um pacto entre as esferas de poder, dado que a necessidade de se alcançar um mínimo de equilíbrio fiscal gera uma disputa, em que cada ente federativo tenta aumentar seus ganhos financeiros e delegar aos outros as responsabilidades ${ }^{5}$.

A existência de heterogeneidades em uma nação, de cunho territorial, étnico, linguístico, socioeconômico, cultural ou político, é uma condição para se organizar uma estrutura federativa, buscando-se manter a estabilidade social: Se um país desse tipo não constituir uma estrutura federativa, dificilmente a unidade nacional manterá a estabilidade social ou, no limite, a própria nação corre risco de fragmentação ${ }^{6}$.

A importância da federação estaria ligada à capacidade de se construírem parcerias entre as unidades territoriais, na tentativa de solução dos conflitos existentes. Neste sentido, o federalismo e os pactos estão intrinsecamente conectados, conforme destaca Daniel Elaza, citado por Fernando Luis Abrucio 6 : O termo "federal" é derivado do latim foedus, que [...] significa pacto. Em essência, um arranjo federal é uma parceria, esta- 
belecida e regulada por um pacto, cujas conexões internas refletem um tipo especial de divisão de poder entre os parceiros, baseada no reconhecimento mútuo da integridade de cada um e no esforço de favorecer uma unidade especial entre eles.

Entretanto, sendo o federalismo marcado pela diversidade e pelo conflito, um dos desafios dos Estados federais é, justamente, a criação de propostas que permitam realizar uma adequação entre a competição e a cooperação existentes. A busca por este equilíbrio é essencial nas relações intergovernamentais sob o federalismo. Para tanto, devem ser estimulados mecanismos de parceria que sejam aprovados pelos entes federativos, sem a imposição de formas de participação conjunta. Os pactos intergestores situam-se nesse propósito, na tentativa de superação do desequilíbrio entre cooperação e competição, estabelecendo uma prática política que fortalece os laços de parceria entre as esferas de gestão.

São características básicas de uma federação heterogênea como a brasileira, conforme Abrucio e Soares ${ }^{7}$ :

$\checkmark$ a autonomia dos governos subnacionais, o que implica reconhecer a existência de uma multiplicidade de poderes;

$\checkmark$ a interdependência dos governos subnacionais e autônomos;

$\checkmark$ a ideia republicana de coisa pública, de uma sociedade que controle o Estado;

$\checkmark$ a subsidiariedade, que se refere à criação de mecanismos para compensar a desigualdade entre os entes federativos.

A adoção de pactos intergestores resulta do processo de amadurecimento destes princípios federativos. A formação de alianças entre os governos federal, estaduais e municipais favorece a constituição de parcerias, de redes colaborativas que fortalecem o pacto federativo e, em última instância, ajudam a diminuir as desigualdades existentes.

Após a institucionalização do Estado Federativo no Brasil, na década de 1990 foi implementado um extensivo programa de descentralização, principalmente na área das políticas sociais, especialmente na saúde, educação, assistência social e habitação ${ }^{8}$.

A simultaneidade histórica do federalismo e da descentralização tem levado à falsa impressão de eles serem a mesma coisa, adverte Marta Arrecthe ${ }^{8}$. Fazendo a distinção entre os dois processos, a autora afirma que o federalismo diz respeito às formas de distribuição da autoridade política dos Estados nacionais e ressalta que os Estados federativos são uma forma particular de go- verno dividido verticalmente, de tal modo que diferentes níveis de governo têm autoridade sobre a mesma população e território.

A descentralização refere-se à distribuição das funções administrativas entre os níveis de gover$n o^{8}$. A permissão para que um dado nível de governo desempenhe funções de gestão, em uma determinada política, ocorre por meio das mais variadas formas de transferência de recursos e delegação de funções, independentemente da autonomia política e fiscal que possua.

A conjuntura nacional de fortalecimento do federalismo e de estímulo à descentralização vem reforçar o argumento de que a busca pela superação das desigualdades entre os entes subnacionais demanda a implantação de mecanismos institucionais de articulação intergovernamental. O estímulo a formas de cooperação vertical e horizontal, conectando funções e recursos entre os níveis de governo, pode criar as condições para que as políticas públicas sejam desenvolvidas com maior eficiência e eficácia.

Dessa forma, a descentralização é compreendida num contexto de relações intergovernamentais em que, muito mais do que qualquer hierarquia federativa, o fundamental é garantir coordenação, cooperação e controle mútuo, não predatório, entre os níveis de governo ${ }^{9}$ - aspectos que se relacionam ao pacto federativo e, em particular, aos pactos de gestão da saúde.

A descentralização das políticas públicas no Brasil não aconteceu de forma homogênea, destacando-se a política de saúde, que é identificada por Rocha e Faria ${ }^{10}$ como uma das que mais avançaram na definição das atribuiçõoes de cada instância da federação.

$\mathrm{O}$ avanço na descentralização da política de saúde, juntamente com a reconstrução da democracia e do federalismo brasileiro, se constituíram em fatores que impulsionaram a definição para a realização dos pactos de gestão no setor saúde.

Ademais, a construção da política de pactuação foi também influenciada pela Reforma de Estado, iniciada nos anos 1990, durante o Governo Collor (1990-1992), e aprofundada no Governo Fernando Henrique (1995-2002), que encaminhou ao Congresso o Plano Diretor da Reforma do Aparelho do Estado, em 1995 ${ }^{11}$. Este Plano seguiu a tendência das reformas ocorridas nos países centrais, adotando uma concepção de Estado mínimo, que deixa de ser responsável direto pelo desenvolvimento econômico e social para se tornar seu promotor e regulador - um Estado cujas funções seriam estimular, coorde- 
nar e financiar as políticas públicas e não mais executá-las.

A tentativa de se imprimir uma administração gerencial na esfera pública é um dos pontos da Reforma. A definição de metas a serem cumpridas para controle a posteriori dos resultados, dentro do serviço público, exerceu influências na configuração dos pactos intergestores, com negociação de metas e indicadores a serem atingidos e pactuação de ações e responsabilidades.

Portanto, a política de pactuação desenvolvida no âmbito da saúde tem suas origens articuladas à reestruturação do Estado brasileiro. Esta política sofreu influências dos elementos e princípios que estão na reconstrução da democracia, do federalismo, da descentralização política e administrativa e da Reforma do Estado.

\section{Os pactos na saúde}

A Constituição de 1988 produziu consequências para o campo da saúde: a criação do SUS, fruto das lutas do movimento sanitário por mudanças na saúde, marco importante para o setor, com os princípios de descentralização, comando único em cada esfera de governo e controle social. Consta também como determinação o acesso às ações e serviços de saúde de forma universal e a implantação de uma rede de serviços de saúde regionalizada e hierarquizada.

Os avanços alcançados durante a implementação do SUS são inquestionáveis, embora ainda existam desafios a serem superados para a consolidação de um sistema público universal, com capacidade para desenvolver ações de maior qualidade.

A contradição entre uma política de saúde de cunho universalista e a conciliação com os princípios neoliberais, que preconizam o Estado mínimo, buscando sempre a redução dos custos, se constitui no principal dilema vivido pelo SUS.

Interessa nesta discussão destacar os aspectos do Sistema Único que impulsionaram a adoção da política de pactuação da saúde: o processo de descentralização político-administrativa, a criação de instâncias de decisão e pactuação no âmbito do SUS e o estabelecimento da Programação Pactuada Integrada (PPI).

No tocante à descentralização, a gradual transferência de responsabilidades e recursos da esfera federal para as esferas estadual e municipal proporcionou mudanças na gestão da saúde, observando-se o fortalecimento da capacidade institucional de diversos estados e municípios, bem como a expansão da rede de serviços municipais de saúde.

Há diferentes níveis de avanços na implementação da descentralização do SUS, relacionados, principalmente, às desigualdades entre os entes federativos. Além disso, Solla ${ }^{12}$ lembra que há resistências à efetiva e ampla descentralização da saúde. Atribui este fato, principalmente, ao poder político hegemônico conservador, por meio de suas práticas de fisiologismo, assistencialismo e clientelismo, na execução direta das ações e serviços de saúde ou na contratação dos serviços privados, que contribuem para a fragilidade política da saúde como política de Estado ${ }^{12}$.

A convivência entre a política de descentralização do SUS, os conflitos por recursos entre os entes federativos e a construção do pacto é questionada por D'Ávila et al. ${ }^{13}$ : É natural que se indague como é possivel a convivência pacífica de uma politica cujo perfil incorpora uma proposta fortemente descentralizadora e, ao mesmo tempo, exige um pacto federativo mais cooperativo, como o SUS, com relações intergovernamentais marcadas por incessantes conflitos e embates sobre recursos, centralização excessiva, fragmentação institucional, frágil capacidade reguladora e inexpressiva tradição participativa da sociedade ${ }^{13}$.

Estas dificuldades, ao contrário, devem se constituir em fatores de estímulo à realização de pactos de gestão, que são justificados, sobretudo na saúde, pela necessidade de se compartilhar a responsabilidade pela qualidade de vida da população entre as distintas esferas de governo, contribuindo para a consolidação do SUS e de seus princípios. Os pactos de gestão se relacionam à política de descentralização à medida que implicam a divisão de responsabilidades, com a cooperação técnica e financeira entre as esferas de poder, associadas ao incentivo à transparência pública e à participação da população.

A adoção de pactuação na gestão do SUS assume papel estratégico no contexto brasileiro de marcantes diferenças socioeconômicas entre estados e municípios, expressas, no setor saúde, pela distribuição desigual de serviços, tecnologias e profissionais de saúde. Os pactos podem servir de estímulo à cooperação intergovernamental, promovendo incentivos à colaboração técnica e/ou financeira, reduzindo a disputa por recursos e pela delegação de responsabilidades no desenvolvimento das ações.

Os foros de negociação e decisão estruturados e articulados, estabelecidos pela Norma Operacional Básica (NOB) 93 no âmbito do SUS, também foram fatores que impulsionaram a 
adoção da política de pactuação. As Comissões Intergestores Bipartite (CIB) e a Comissão Intergestores Tripartite (CIT) foram constituídas com a finalidade de serem criados espaços de negociação, deliberação e operacionalização da política, integrando diferentes gestores dos sistemas de saúde. Estas instâncias, embora palco de conflitos entre os interesses divergentes das esferas governamentais, funcionam como estruturas de negociação, planejamento e decisão intergestores. Favorecem a cooperação entre as esferas de governo, necessária ao fortalecimento da capacidade gestora do SUS. No que se refere aos pactos da saúde, atuam como espaços de discussão e negociação para a deliberação das diretrizes e dos compromissos estabelecidos entre as esferas de governo.

A criação das CIT e das CIB e o incentivo a elas promoveram a institucionalização do pacto, pois, funcionando como instâncias de estímulo à pactuação, negociação, articulação e integração entre as esferas de gestão, elas favoreceram o processo de descentralização compartilhada ${ }^{14}$.

Os pactos de gestão do SUS foram instituídos pela Norma Operacional Básica de 1996 (NOB/01/96). Partindo-se da negociação de metas, os gestores da saúde pactuam ações e responsabilidades, num processo que se iniciou com as ações desenvolvidas na assistência individual, por meio da Programação Pactuada Integrada (PPI) da Assistência à Saúde, e posteriormente, em 1999, incorporou as ações coletivas, utilizando-se a PPI-ECD (Epidemiologia e Controle de Doenças), em seguida denominada PPI-VS (Vigilância em Saúde).

A NOB 96 reafirmou os princípios básicos do SUS, manteve a definição de papéis entre os poderes federal, estadual e municipal, reforçou a capacidade de gestão dos municípios, ampliando as transferências fundo a fundo a todos os municípios habilitados para as ações básicas, e introduziu na gestão do SUS a PPI, resgatando para o SUS o planejamento integrado entre as instituições, iniciado durante as Ações Integradas de Saúde (AIS), na década de 1980.

A PPI se constitui num instrumento formal de pactuação intergestores. Utilizando-se de uma programação físico-financeira integrada, contempla a alocação de recursos e explicita a distribuição de competências assistenciais entre as três esferas de governo. Busca-se, dessa forma, garantir o acesso da população a ações e serviços de saúde no próprio município ou em outros municípios, que passam a ofertar serviços por meio de encaminhamento formalizado e pactuado.
A formação de novos acordos entre os gestores, induzida pela PPI, serviu de estímulo à regionalização e hierarquização do sistema de serviços de saúde nos estados e contribuiu para o fortalecimento da CIB, como espaço permanente de discussão, decisão e afirmação de compromissos intergestores.

No entanto, Baptista ${ }^{15}$ afirma que a utilização da PPI, com tetos máximos já estabelecidos para cada estado, não possibilita o avanço sobre o investimento desejável e compatível com as necessidades de saúde de cada localidade, reproduzindo uma lógica perversa de alocar recursos escassos. A autora questiona essa lógica, ao afirmar que ela não favorece o pacto nem a integração entre gestores: Se toda negociação é feita sobre tetos máximos, que na verdade são mínimos, como o gestor pode abrir mão de qualquer recurso em solidariedade ou cooperação com o outro?

Entretanto, tal situação reafirma a necessidade de construção do diálogo e entendimento entre os gestores, enxergando-se nos pactos a possibilidade de materialização de acordos, não só para a repartição dos recursos mas, principalmente, para o estabelecimento de uma rede colaborativa intergestores, enfatizando-se a divisão da responsabilidade sanitária, assegurando o acesso da população às ações e serviços de saúde.

A Norma Operacional da Assistência à Saúde (Noas 01/01), publicada pela Portaria GM n 95, reafirmou a importância da PPI como uma ferramenta de planejamento, voltada para a articulação das três esferas de gestão do SUS e para a integração das áreas de promoção e da assistência à saúde, de epidemiologia e controle de doenças, e de vigilância sanitária.

A realização dos pactos no âmbito da Assistência, da Atenção Básica e da Vigilância em Saúde serviu de estímulo para a proposição de outros pactos no SUS, a exemplo do Pacto Nacional pela Redução da Mortalidade Materna e Neonatal, lançado em março de 2004.

Medina et al. ${ }^{16}$, analisando o Pacto dos Indicadores da Atenção Básica, ressaltam a sua capacidade de estabelecer uma nova maneira de conduzir a gestão do SUS, contribuindo para que as ações de monitoramento e avaliação sejam incorporadas à cultura dos serviços, deixando de ser desenvolvidas como ritos meramente administrativos. Os autores consideram a existência de dois tipos de pactuação: o burocrático e o dinamizador. O primeiro é conduzido burocraticamente, de maneira pontual, fragmentado, sem promover a articulação entre os setores das secretarias e sem visibilidade perante as instâncias 
de deliberação e pactuação do SUS. O "pacto dinamizador" é desenvolvido mediante um processo que aglutina experiências e práticas, buscando fortalecer a implementação da municipalização, sendo utilizado para monitorar e avaliar ações e serviços de saúde, integrado ao processo de trabalho, promovendo a qualificação da gestão, com visibilidade e credibilidade perante as instâncias de deliberação e pactuação do SUS.

A avaliação e a tipologia propostas por esses autores referem-se aos pactos da atenção básica; no entanto, por extensão, poder-se-ia afirmar que tal situação se repetiria ao serem observados os demais pactos realizados no âmbito da saúde. Municípios e estados aderem à pactuação de metas e indicadores, motivados preferencialmente pelo recebimento de recursos financeiros, sem definição de mecanismos de monitoramento e avaliação das metas pactuadas. Dessa forma, os pactos, na maioria das vezes, são conduzidos de forma cartorial, visando ao cumprimento dos ritos de habilitação, preconizados pela legislação, para o recebimento de verbas.

O Pacto pela Saúde, aprovado pela CIT em janeiro de 2006, ao reunir os pactos desenvolvidos no SUS em um só, busca dissolver a dicotomia existente entre os pactos da assistência (ações individuais) e da vigilância em saúde (ações coletivas). Traz como inovação a extinção da habilitação para estados e municípios. Em sua retóri$\mathrm{ca}$, visa instituir de maneira mais clara a responsabilização solidária no SUS, em que todos os gestores são considerados plenos de suas responsabilidades, substituindo o processo de habilitação pela adesão ao Termo de Compromisso e Gestão (TCG).

Solla ${ }^{12}$ identifica cinco mudanças apresentadas pelas Portarias no 399/GM (de 22 de fevereiro de 2006) e no 699/GM (de 30 de março de 2006) que aprovaram e regulamentaram as diretrizes operacionais do Pacto pela Saúde:

$\checkmark$ a substituição do processo de habilitação pela formalização de termos de compromisso e gestão;

$\checkmark$ a proposta de regionalização solidária como eixo da descentralização;

$\checkmark$ a integração das várias formas de repasse de recursos federais para estados e municípios em blocos de financiamento;

$\checkmark$ a cobrança da explicitação dos recursos de custeio próprios das esferas municipal e estadual;

$\checkmark$ a unificação dos processos de pactuação de indicadores a partir de 2007.
O Pacto pela Saúde, por meio de seus três componentes - o Pacto pela Vida, o Pacto em Defesa do SUS e o Pacto de Gestão do SUS -, define o TCG como o instrumento formalizador deste pacto e reafirma o compromisso entre os "gestores das ações de saúde" com atribuições definidas e metas a cumprir, não havendo mais município ou estado habilitado e não habilitado. O TCG contém as metas e objetivos do Pacto pela Saúde, as responsabilidades e atribuições de cada gestor e os indicadores de monitoramento.

A dimensão do Pacto pela Vida inclui compromissos e metas relacionados à saúde do idoso, câncer do colo de útero e de mama, mortalidade infantil e materna, doenças emergentes e endemias (com ênfase na dengue, hanseníase, tuberculose, malária e influenza), promoção da saúde e atenção básica.

O componente Pacto em Defesa do SUS envolve ações concretas e articuladas pelas três instâncias federativas no sentido de reforçar o SUS como politica de Estado mais do que política de governos; e de defender, vigorosamente, os princípios basilares dessa política pública, inscritos na Constituição Federal ${ }^{17}$. Para tanto, propõe uma mobilização social permanente, num movimento de repolitização da saúde e de mobilização por mais recursos orçamentários e financeiros para a saúde.

O terceiro componente do Pacto pela Saúde, o Pacto de Gestão, estabelece as responsabilidades de cada ente federado, buscando diminuir as competências concorrentes, contribuindo, assim, para o fortalecimento da gestão compartilhada e solidária do SUS ${ }^{16}$. Para o alcance deste objetivo, determina como prioridades: a definição da responsabilidade sanitária de cada instância gestora do SUS, superando o processo de habilitação; e o estabelecimento de diretrizes para a gestão do SUS, com ênfase na descentralização, regionalização, financiamento, programação pactuada e integrada, regulação, participação e controle social, planejamento, gestão do trabalho e educação na saúde.

Foram, então, instituídas as bases para a construção do diálogo entre as esferas de governo, vislumbrando-se, por meio do Pacto pela Saúde, a possibilidade de materialização de acordos voltados à repartição dos recursos e responsabilidades, mas principalmente para o estabelecimento da responsabilização solidária entre os gestores, necessária para assegurar o acesso da população às ações e aos serviços de saúde. 

e da Reforma do Estado. Foram também analisados os aspectos internos ao SUS que influenciaram seu desenvolvimento, até a constituição do Pacto pela Saúde: o processo de descentralização político-administrativa, a criação de instâncias de decisão e pactuação e o estabelecimento da Programação Pactuada Integrada (PPI).

A recente reunião dos pactos realizados no âmbito da saúde em um só - o Pacto pela Saúde - e as mudanças decorrentes deste movimento de unificação representam, sem dúvida, avanços na política de pactuação e na condução da gestão do SUS, principalmente no aspecto da divisão da responsabilização sanitária entre os entes federados. Longe de avaliações precipitadas - afinal, o Pacto pela Saúde só ocorreu a partir de 2007 -, tem-se a preocupação com o fato de que tais avanços, isoladamente, não garantem a adesão dos gestores, a execução das metas, o alcance dos indicadores pactuados e muito menos o uso do pacto de maneira dinamizadora. Trata-se de um processo mais complexo, sendo necessário o envolvimento dos gestores, dos técnicos, da população e das instâncias representativas do SUS para que o Pacto pela Saúde não represente apenas mais uma tentativa de imprimir uma gestão eficiente no SUS, pautada pelo diálogo entre as instâncias gestoras. A esta retórica é necessário o acréscimo de iniciativas no sentido de garantir mecanismos reais de cooperação técnica e financeira entre essas instâncias que possam, efetivamente, favorecer a execução das ações e o controle social. Esses mecanismos de cooperação é que irão permitir a superação do status pré-hobbesiano de guerra de todos contra todos, em que alguns estados e municípios buscam, cada vez mais, aumentar recursos e delegar funções, postura incompatível com os princípios do pacto federativo e do Pacto pela Saúde. O governo federal, no exercício do papel de coordenador e indutor do processo de pactuação, deve buscar arbitrar esses conflitos e incentivar a atuação conjunta entre as esferas de poder, contribuindo para a constituição de uma rede federativa mais solidária.

Neste sentido, concorda-se com a afirmação de Trevisan e Junqueira ${ }^{18}$ : A construção do "pacto de gestão" poderá dar uma outra operacionalidade ao Sistema Único de Saúde. Não é "remédio milagroso", nem terá o poder de superar as dificuldades operacionais da rede. Iniciar a construção do "pacto" é, exatamente, assimilar uma outra forma de superação das dificuldades das ações em rede do SUS.

A consolidação da política de pactuação, assim como de qualquer política pública em países democráticos, é um processo dinâmico, que envolve negociação e articulação permanentes entre os atores e as instâncias envolvidas. A capacidade de articulação entre essas forças é que irá indicar os avanços e recuos durante a implementação dessa política no Brasil.

\section{Colaboradores}

JV Guerreiro e MAF Branco participaram igualmente de todas as etapas de elaboração do artigo. 


\section{Referências}

1. Hobbes T. Leviatã. São Paulo: Abril Cultural; s. d. (Coleção Os Pensadores).

2. Rousseau JJ. Do contrato social. São Paulo: Abril Cultural; s. d. (Coleção Os Pensadores).

3. Bresser-Pereira LC, Nakano Y. O contrato social ausente. Estado e Sociedade 1998; 12(2):13-39.

4. Bresser-Pereira LC. Pactos políticos: do populismo à redemocratização. São Paulo: Brasiliense; 1985.

5. Peppe AM, Pereira ES, Brito FRCD, Macedo ME. Reflexões sobre a federação brasileira. Rev Administração Pública 1997; 31(4):157-182.

6. Abrucio FL. A coordenação federativa no Brasil: a experiência do período FHC e os desafios do Governo Lula. Rev Sociol Pol 2005; 24:41-67.

7. Abrucio FL, Soares MM. Redes federativas no Brasil: cooperação intermunicipal no Grande $A B C$. São Paulo: Fundação Konrad Adenauer; 2001.

8. Arretche M. Relações federativas nas políticas sociais. Educ Soc (Campinas) 2002; 23(80):25-48.

9. Abrucio FL. A experiência de descentralização: uma avaliação. In: Balanço da reforma administrativa no Brasil: a nova gestão pública. Brasília: MP, SEGES; 2002.

10. Rocha CV, Faria CAP. Descentralização e cooperação intermunicipal no Brasil. In: Anais VIII Congresso Luso-Afro-Brasileiro de Ciências Sociais. Coimbra, 16-18 set. 2004.

11. Brasil. Ministério da Administração Federal e Reforma do Estado. Plano Diretor da Reforma do Estado. Brasília: Ministério da Administração Federal e Reforma do Estado; 1995. (Documentos da Presidência da Reforma do Estado).

12. Solla JJSP. Avanços e limites da descentralização no SUS e o "Pacto de Gestão". Rev Baiana de Saúde Públic 2006; 30(2):332-348.
13. D’Ávila ALV, Lima LD, Oliveira RG. Descentralização e federalismo: a política de saúde em novo contexto - lições do caso brasileiro. Cien Saude Colet 2002; 7(3):493-507.

14. Carvalho GCM. O financiamento público federal do Sistema Único de Saúde - 1988-2001 [tese]. São Paulo. Faculdade de Saúde Pública, Universidade de São Paulo; 2002.

15. Baptista TWF. Politicas de saúde no Pós-Constituinte: um estudo da política implementada a partir da produção normativa dos poderes Executivo e Legislativo no Brasil [tese]. Rio de Janeiro: Instituto de Medicina Social, Universidade do Estado do Rio de Janeiro; 2003.

16. Medina MG, Aquino R, Carvalho ALB. Avaliação da atenção básica: construindo novas ferramentas para o SUS. Divulgação Saúde para Debate 2000; 21:15-28.

17. Brasil. Portaria n ${ }^{\circ} 399 /$ GM. Divulga o Pacto pela Saúde 2006 - Consolidação do SUS - e Aprova as Diretrizes Operacionais do Referido Pacto. Diário Oficial da União 2006; 22 fev.

18. Trevisan LN, Junqueira LAP. Construindo o "pacto de gestão" no SUS: da descentralização tutelada à gestão em rede. Cien Saude Colet 2007; 12(4):893902.

Artigo apresentado em 19/03/2008

Aprovado em 29/07/2008

Versão final apresentada em 01/09/2008 